\title{
ESTILOS DE LIDERANÇA: UM ESTUDO NAS AGÊNCIAS DE UM BANCO DE VAREJ̧O PÚBLICO EM SANTA CATARINA
}

\author{
Denise Del'Prá Netto Machado 1 \\ Acilão Gonçalves Antunes 2
}

\begin{abstract}
Resumo: Este trabalho trata da verificação dos perfis dos gestores das unidades organizacionais de um Banco de Varejo Público. As referências teóricas restringiram-se às Teorias das Características de Personalidade (TC), Estilos Comportamentais (EC), Sistêmicas Situacionais (SS), Gestão do Sentido (GS) e Arquitetura Organizacional (AO). A metodologia de pesquisa foi a de levantamento e survey, com a aplicação de questionário com 30 pares de afirmações, em que cada uma das linhas teóricas é representada por 12 afirmações. 0 objetivo foi identificar e avaliar os estilos de gerência adotados por um grupo de nove administradores, em agências localizadas no estado de Santa Catarina. As agências pesquisadas guardam similaridades em relação a sua estrutura e clientela, atuam no interior e têm entre 15 e 30 funcionários. A verificação do perfil partiu de como o gestor se vê e de como é visto pelos subordinados. Buscou-se aliar à pesquisa, aspectos demográficos da amostra. A pesquisa não revelou diferenças significativas em relação aos perfis traçados. Houve uma preponderância maior nas freqüências em relação às tipologias Gestão do Sentido (GS) e Arquitetura Organizacional (AO). Não ficou evidenciado que as variáveis demográficas, como tempo de banco, escolaridade, estado civil e gênero tivessem relação com os resultados obtidos.
\end{abstract}

Palavras-chave: Estilos de liderança. Banco de varejo público. Liderança.

\section{INTRODUÇÃO}

As organizações estão mudando. As estruturas mecânicas estão se transformando em sistemas orgânicos, que caracterizam uma nova forma de organização, ainda não plenamente desenvolvida, porém, baseada em grupos participantes, com um sistema administrativo orgânico integrado e internamente homogêneo (LIKERT, 1971). A forma de organização por grupos superpostos é sua estrutura primária. Além das aptidões técnicas e administrativas necessárias, 0 administrador também possuirá uma filosofia básica de liderança, que colocará ênfase no eficaz funcionamento do grupo e nos relacionamentos cooperativos. As organizações atuais valorizam o trabalho em equipe ante 0 individualismo.

As equipes multidisciplinares tendem a desempenhar um papel cada vez mais intensivo. A razão para isso é que o aumento do conhecimento obriga a especializações maiores. Por outro lado, aumenta a complexidade dos problemas e das oportunidades, abrangendo, cada vez mais, aspectos e especialidades diferentes (LACOMBE; HEIBORN, 2003; BOLWIJN; KUMPE, 1996).

Um fator sobressai-se nos estudos sobre as organizações: a liderança. Parece difícil compreender o sucesso de uma organização sem compreender os conceitos de gerência e de liderança e suas possíveis relações com a efetividade das organizações. Para Moscovici (1995, p. 169):

\footnotetext{
1 Programa de Pós-Graduação em Administração, FURB, Blumenau, SC. E-mail: delpra@furb.br

2 Mestre em Administração, FURB, Blumenau, SC. E-mail: cilaoantunes@ibest.com.
} 
Os grupos humanos necessitam de líderes competentes para sobreviver e desenvolver plenamente seus recursos e potencialidades. Igualmente, as organizações sociais necessitam de líderes competentes (dirigentes/executivos/gerentes) para sua sobrevivência e desenvolvimento cabal de recursos e potencialidades.

No presente trabalho, o ponto de referência são as realidades vivenciadas por esses atores, tanto organizacionais como macro-sociais. É difícil conformar, em termos de atributos pessoais, uma função estratégica para a organização cujo foco de atuação é, de um lado, impessoal e pragmático cuja essência é a busca dos resultados racionais e esperados; de outro, com significâncias humanas, construído à luz dos relacionamentos que compõem a dinâmica social do ambiente, assumindo uma faceta pessoal e subjetiva (FINKELSTEIN; HAMBRICK, 1996).

$\mathrm{Na}$ organização pesquisada - um banco de varejo - os gerentes foram formados a partir de postulados burocráticos, existentes na estrutura organizacional tradicional - piramidal - em que 0 espaço para a criação raramente surge. A formação das equipes em que trabalham não raro é por justaposição, isto é, a alocação do pessoal não é em sua essência uma decisão do gerente. Nesse caso, o líder não forma a sua equipe. Ele é formado a partir desta quando não é simplesmente indicado a essa condição. Como asseveram Smircich e Morgan (1997), a organização formal tende a coibir 0 processo de liderança, o qual é observado em situações naturais. Caracteriza-se, assim, como uma forma de organização humana em papéis, relacionamentos e práticas predeterminados, que oferecem um esquema de como os relacionamentos dos membros da organização devem ser estruturados, coibindo dessa forma, a naturalidade da construção das relações.

As análises dos perfis de liderança, nas organizações, têm partido de características associadas a traços, comportamentos, contextos, posturas e tipo de organizações, em que se desenvolve 0 processo. Portanto, 0 exercício da função de liderança transita por nuances comportamentais, que estão associadas a várias tipologias cuja delimitação sucinta parece não fornecer uma compreensão mais fundamentada.

O estilo de gerência é um fator que mostra a forma predominante ou o comportamento típico da ação do gerente no relacionamento com a equipe, no processo de influenciar indivíduos ou grupos, para atingir os objetivos (KOYS; DECOTIIS apud ALMEIDA, 1991). Esse pressuposto levanta 0 questionamento de quais características têm esses líderes nas organizações bancárias, como os liderados os vêem e que perfis são percebidos.

A literatura tem traçado posturas e atitudes para os líderes e esses autores têm pesquisado a problemática relativa à liderança. Eles propõem que a liderança transite entre as seguintes tipologias:

a) dos traços de personalidade (TC);

b) dos estilos gerenciais adotados (EC);

c) dos aspectos situacionais ou contingenciais, em que é desempenhada a função de liderança (SS);

d) as teorias da administração do sentido (GS);

e) as com ênfase na arquitetura organizacional (AO).

As agências pesquisadas neste trabalho têm um mesmo perfil de mercado, atuam no ramo de varejo diversificado, isto é, atendem a pessoas físicas e pequenas e micro empresas em cidades pequenas, no interior do estado de Santa Catarina. Têm, em seus quadros funcionais, entre quinze e trinta funcionários. Os recursos tecnológicos e o quadro de pessoal são diretamente proporcionais ao PIB - Produto Interno Bruto - das praças em que estão localizadas, assim como às metas de cada unidade. Diante disso, as condições em que atuam os gerentes - líderes - podem ser enquadradas como similares. 
Do problema central se extraem as seguintes perguntas de pesquisa:

a) o perfil de liderança do gestor varia significativamente em sua própria ótica dentre as diferentes agências?

b) o perfil de liderança do gestor varia significativamente dentre as diferentes agências na ótica dos liderados?

c) a percepção que o gestor tem do seu perfil de liderança coincide com as percepções dos liderados?

d) que variáveis demográficas qualitativas se associam com a percepção que os liderados têm do gestor?

A partir dessas questões, estabelece-se o objetivo: entender as diferenças e as similaridades entre a percepção do gestor sobre seu perfil de liderança e a percepção dos liderados, com base nas teorias de liderança particularizadas no estudo. Esse objetivo coloca outros, de caráter específico:

a) analisar se há diferenças nos perfis dos gestores dentre as agências, segundo as teorias de liderança;

b) verificar a relação entre a introspecção, que o gestor faz de seu perfil, e as percepções dos liderados;

c) verificar as variáveis demográficas que se associam à percepção que os liderados têm dos perfis dos seus gestores.

O pressuposto central é o de que os perfis de liderança dos gestores das agências não variam significativamente em termos de sua percepção, quanto na forma como são percebidos pelos subordinados.

Adiciona-se, ao pressuposto central, os que seguem:

a) há mais similaridades que diferenças significantes entre as introspecções dos gestores sobre seus perfis de liderança e as percepções dos liderados;

b) as variáveis demográficas qualitativas, que se associam com a percepção que os liderados têm do gestor, são: tempo de banco, escolaridade, estado civil e sexo.

\section{REFERENCIAL TEÓRICO}

No referencial teórico são focadas as teorias consideradas clássicas na literatura, sobre a liderança. Esse enfoque deve-se à possibilidade de uma maior facilidade na diferenciação das diversas proposições sobre a temática. Trabalha-se com cinco correntes, as dos traços ou de características de personalidade; as de estilos ou comportamentos; as sistêmicas ou situacionais; as que estudam a gestão do sentido; e as com ênfase na gestão da arquitetura organizacional.

\subsection{TEORIA DOS TRAÇOS}

A primeira sistematização dos estudos sobre liderança - Teoria dos Traços - enfatizava principalmente as qualidades pessoais do líder. Essa abordagem ficou assim conhecida porque seus pesquisadores propunham, como ponto de partida, que os líderes deveriam possuir certas 
características de personalidade especiais, as quais seriam basicamente os principais facilitadores no desempenho do papel de liderança. Houve, desde o início dos estudos dessa abordagem, no começo do século XX, uma preocupação em diferenciar líderes de não líderes. Dessa forma, os líderes passaram a ser entendidos como seres diferentes das demais pessoas, pelo fato de possuírem alguns traços considerados particulares, profundos, responsáveis não só por fazê-los emergir como tal, como também por mantê-los em suas posições (BERGAMINI, 1994).

Bryman (apud BERGAMINI, 1994, p. 28-29) defende que existem três grandes tipos de traços, sobre os quais a literatura refere-se:

\begin{abstract}
Fatores físicos, tais como altura, peso, físico, aparência e idade. Habilidades características, tais como inteligência, fluência verbal, escolaridade e conhecimento. Cita ainda uma ampla gama de aspectos de personalidade, como: moderação, introversão, extroversão, dominância, ajustamento pessoal, auto-confiança, sensibilidade interpessoal e controle emocional.
\end{abstract}

Para Bergamini (1994), os estudos desenvolvidos no período de aproximadamente quarenta anos e que tiveram como sustentação metodológica avaliar a existência de um determinado traço comportamental, entre um grupo de pessoas que desempenhassem a função liderança, em contraponto a um outro grupo que não estivesse nessa posição, tiveram resultados aceitáveis. Ao final, foi possível chegar a alguma correlação positiva entre as pessoas que estavam na função liderança e um determinado conjunto de traços. As conclusões, no entanto, não encerraram as inúmeras interrogações ainda existentes sobre a difícil compreensão da liderança. Novas abordagens viriam buscar essa compreensão.

\title{
2.2 TEORIA DOS ESTILOS OU COMPORTAMENTOS
}

Desvanecida a esperança de se encontrar os traços mágicos de personalidade, que pudessem levar à identificação do líder, os pesquisadores voltaram-se para o estudo do comportamento do líder. Dessa forma, especialmente após a II Grande Guerra Mundial, um grande esforço foi feito para determinar, mais precisamente, como caracterizar um comportamento eficaz de liderança. No enfoque dos traços, a suposição básica é a de que o líder nasce como tal. No enfoque dos estilos, aceita-se que, uma vez sendo conhecido o comportamento responsável pela liderança eficaz, as pessoas podem ser treinadas para exibir tal comportamento, conseguindo, assim, transformarem-se em melhores líderes (BERGAMINI, 1994).

Em relação à temática comportamental, surgiram vários estudos. Os mais amplos e precisos foram dirigidos por Carroll Shartle, na Universidade de Ohio, no fim da década de 40 e primeiros anos da década de 50. A descoberta central desses estudos foi que o comportamento de liderança poderia ser classificado, de forma útil, através de dois fatores independentes, denominados iniciar estrutura e consideração (REDDIN, 1986).

Iniciar estrutura relaciona-se ao planejamento, bem como à organização do trabalho em tarefas. Já consideração refere-se à manutenção de relações. Para Reddin (1986), a utilidade da compreensão desses dois tipos de comportamento está em facilitar a compreensão do comportamento gerencial. Esses dois fatores geralmente são descritos como independentes, porque a extensão na qual um gerente usa um deles não ajuda a prever a extensão do uso do outro.

"Este ponto é vital, pois significa que um gerente pode estar usando os dois em grande quantidade, os dois em pequena quantidade, grande quantidade de um e pequena quantidade de outro, ou qualquer combinação de quantidades várias dos dois fatores." (REDDIN, 1986, p.36).

Um dos enfoques preferidos sobre comportamento popular, após o início dos anos 60, foca 0 trabalho de Douglas McGregor e suas teorias X e Y. Para Clemens e Mayer (1989), a partir dos 
estudos de McGregor (apud CLEMENS; MAYERS, 1999), exacerbou-se o caráter dicotômico da abordagem em muitos textos de administração, sendo transmitida essa visão em programas de treinamento para executivos. Nos cursos corporativos, a impressão que se passou a partir dos estudos de McGregor é que se o administrador for "Y", o mesmo acertará com seus subordinados, de forma simplista, considerando os empregados como quase perfeitos, verdadeiros dínamos cheios de desinteressada dedicação.

Não há entre os pesquisadores um marco histórico rígido, que delimite os estudos dos estilos, dos empreendidos pelos pesquisadores do enfoque situacional, que venha o suceder nas correntes teóricas sobre liderança. A literatura menciona pesquisas feitas já a partir do final dos anos 40 , citando trabalhos sobre o estilo de comportamento do líder e que vêm se estender até o início do novo milênio, apesar dessa corrente não ser mais preponderante nos estudos contemporâneos.

\subsection{AS TEORIAS SISTÊMICAS OU SITUACIONAIS}

A liderança situacional foi desenvolvida por Paul Hersey e Kenneth $\mathrm{H}$. Blanchard no final dos anos 60 (GARDNER, 1990). A liderança situacional consiste na interação de três fatores importantes: a dose de orientação e direção oferecida pelo líder; a dose de apoio sócio-emocional proporcionada pelo líder e o grau de desenvoltura de quem está sendo orientado (o seguidor), para cumprir uma tarefa específica. Esses fatores estão presentes em qualquer situação de liderança e podem ser facilmente compreendidos por membros de qualquer cultura. Para essa abordagem, não existe uma "maneira melhor" de influenciar as pessoas. Portanto, o modelo é útil, sobretudo para organizações multiculturais onde a flexibilidade é necessária (GARDNER, 1990).

Os leigos, gerentes e acadêmicos, têm se questionado se há um estilo ideal de liderança. Quando se foca o pragmatismo da eficácia organizacional, há uma decisão racionalmente embasada, que pode ser sustentada ao se optar por um ou outro estilo? Como afirma Reddin (1986), as pesquisas, a exemplo das desenvolvidas por psicólogos como L. Cosh e J. R. P. French Jr., corroboram uma mesma visão sobre o assunto: nenhum estilo é naturalmente mais eficaz que os outros. A eficácia depende da adequação do estilo à situação em que é usado. Para aprender a ser eficaz, o gerente precisa aprender a "ler" as situações (REDDIN, 1986).

A personalidade não é o único fator determinante do comportamento dos gerentes, na condição de líderes no cotidiano das organizações do trabalho. Não seria difícil predizer 0 comportamento de alguém, caso se conhecesse apenas a situação em que o comportamento é observado. A uniformidade de comportamento em um funeral, em um jogo de bola ou em uma reunião de equipes de trabalho é marcante. A maioria das assimetrias no modo de as pessoas agirem são relativamente insignificantes, quando consideramos o quanto do comportamento é determinado pelo contexto social. (FIEDLER; CHEMERS, 1981). Para esses autores, não é de surpreender que a situação represente papel relevante em qualquer tentativa que se faça, no sentido de compreender a liderança.

O tipo de organização, seja ela mecanicista ou orgânica, também influencia, sobremaneira, 0 clima organizacional, que, por sua vez, influencia no tipo de liderança a ser adotado. Organizações mecanicistas tendem a ter estruturas hierárquicas restritas, normas rígidas e formalizadas, baixa confiança recíproca entre seus membros e um fluxo comunicativo, sobretudo, descendente. As organizações orgânicas exibem estruturas mais frouxas, um fluxo comunicativo multidimensional, dirigido para os companheiros e para os superiores, tanto quanto para os subordinados, e um alto grau de confiança e tolerância nas relações entre os companheiros de trabalho (FIEDLER; CHEMERS, 1981; GARDNER, 1986; GARDNER; CUMMINGS, 1988).

Outros fatores que influenciam o comportamento de liderança são a finalidade do grupo - para que foi constituído - e o tipo de tarefa que o grupo desempenha. Nesse contexto, os atributos, as 
motivações e as capacidades dos empregados têm igual probabilidade de afetar o comportamento do líder.

Dentro da abordagem situacional, há teorias mais recentes que têm buscado investigar as condições específicas sob as quais um ou outro comportamento de liderança é o mais eficiente. Teoria relevante, nesse sentido, é o Modelo de Dependência (Contingency Model) da eficácia em liderança, de acordo com o qual o desempenho de um grupo depende tanto do sistema motivacional do líder como do grau em que este último exerce controle e influência em uma dada situação da "vantagem situacional" (FIEDLER; CHEMERS, 1981). Essa teoria encara o contexto de liderança como uma "situação", em que o líder procura satisfazer a seus objetivos, tanto quanto aos da organização. Portanto, o grande mérito dos pesquisadores ditos contingenciais reside no fato de terem dado início a preocupações com o aspecto motivacional, colocando-o como uma variável relevante para o estudo da psicodinâmica da liderança.

\subsection{AS TEORIAS DA GESTÃO DO SENTIDO}

Os enfoques já tratados particularizam aspectos como características de personalidade, formas de comportamento e contextos situacionais. Uma abordagem mais complexa, com uma perspectiva mais ampla de análise da liderança, vem contribuir com os estudos até então desenvolvidos sobre a temática. Para essa abordagem, o líder aparece como figura principal e grande protagonista do que se denomina administração do sentido.

Entre os seus focos de estudo estão os aspectos referentes às necessidades dos liderados e as suas expectativas quanto ao papel da empresa em satisfazê-las (BERGAMINI, 1997). Essas necessidades têm um potencial sinérgico intrínseco, que é o recurso de que dispõem para empreender suas ações - motivação intrínseca - na direção daqueles objetivos que fazem sentido para si mesmo. Sob o ponto de vista do líder, a abordagem ressalta que a relevância do papel do líder repousa em sua habilidade de identificar essas necessidades, em sua sensibilidade interpessoal, posicionando-se, aos olhos dos liderados, como um facilitador da expressão dessas necessidades, e o que busca associar a satisfação dessas necessidades com os objetivos organizacionais. 0 sentido que o homem dá ao mundo que o rodeia depende de suas necessidades, carências e expectativas interiores, em um dado momento. Logo, esse sentido tem alicerces intrínsecos. A fonte mais importante de recursos pessoais, para se atingir o ajustamento motivacional, são as informações que se têm do mundo à volta de cada um. Grande parte dessas informações tem origem no comportamento do líder. São eles que ajudam a transformar as necessidades dos seguidores em esperanças positivas e em aspirações (BERGAMINI, 1994).

Para a abordagem gestão do sentido, os líderes eficazes não tratam apenas de decisões explícitas do momento - a aprovação de um orçamento, a divulgação de uma política, o feedback a um subordinado -, mas também com o mundo, em parte consciente, em parte oculto, de necessidades e esperanças, idéias e símbolos dos sujeitos sociais pares - os liderados. Os líderes servem como modelos, simbolizam a unidade e a identidade do grupo, são eles que retransmitem as histórias carregadas de significados partilhados por todos. 0 impacto que eles exercem como exemplos é significativo. A mensagem que enviam para os seguidores, naquilo que prestam atenção, no modo como lidam com incidentes críticos, na correspondência entre suas palavras e seus atos, carregam uma marcante reconfiguração da realidade aos olhos dos parceiros grupais (GARDNER, 1990).

Para Bergamini (1994), compreender a dinâmica da motivação é uma condição para que o líder consiga maior eficácia no processo de interação com seus subordinados. Para essa autora, esse tipo de compreensão passaria por diferenciar motivação intrínseca de motivação extrínseca. Não há dúvidas em relação à clara importância da motivação intrínseca sobre a motivação extrínseca. A 
primeira merece especial atenção dos verdadeiros líderes. A valorização dos fatores intrínsecos ou dos fatores extrínsecos determinará, como resultado, estilos de liderança diferentes.

Ninguém poderá ser um líder eficaz se não entender que, antes de tudo, cada um vê, no próprio trabalho, a oportunidade de realizar as suas próprias potencialidades, buscando conseguir uma indispensável ligação com a comunidade em sentido mais amplo (BERGAMINI; CODA, 1997). A sensibilidade do líder, em perceber as significâncias que o trabalho assume para os sujeitos na organização, talvez seja um dos atributos mais relevantes para a compreensão da liderança, a partir das relações entre o líder e os liderados.

Particularizar a forma pela qual o sentido é criado, mantido e mudado oferece um poderoso meio de entender a natureza fundamental da liderança como um processo social. A compreensão da maneira pela qual as atitudes do líder tentam delinear e interpretar situações para guiar os membros da organização (motivar), dentro de uma interpretação comum da realidade, poderá levar a compreensão de como funciona a liderança, ao criar uma base para a atividade organizada. Essa dinâmica pode ser representada em termos de relacionamento entre figura e fundo. A ação do líder, nesse sentido, envolve uma figura que se move - um fluxo de ações e declarações (isto é, aquilo que os líderes fazem), dentro do contexto de uma base em movimento - envolve também ações, declarações e fluxo geral de experiências, que constituem a situação que está sendo administrada. A liderança é um fenômeno identificável dentro do seu contexto mais amplo, como um modo de ação que procura dar contornos a esse mundo de significâncias. A liderança funciona influenciando as relações entre a figura e o fundo, conseqüentemente, entre o sentido e a definição do contexto (SMIRCICH; MORGAN, 1997).

Administrar o sentido é permitir que os indivíduos orientem a si mesmos na a obtenção dos fins desejados. Nesse empenho, o uso de linguagem, do ritual, da ação, estórias, mitos e construções simbólicas de todos os tipos podem desempenhar importante papel (PFEFFER, 1981; PONDY, FROST, MORGAN \& DANDRIDGE, 1982; SMIRCICH, 1982). Esses aspectos constituem importantes recursos para a administração do sentido. Por meio de palavras e imagens, bem como de ações simbólicas e gestos, os líderes podem estruturar a atenção, evocando padrões de significado, que dão a eles considerável controle sobre a situação que está sendo administrada.

\subsection{AS TEORIAS COM ÊNFASE NA ARQUITETURA ORGANIZACIONAL}

Contemporaneamente, há visões diferentes daquelas tipologias já mencionadas no presente trabalho. Essas visões deixam para trás também as características de grupos específicos de trabalho. O que de novo essas abordagens trazem, como a de Nadler (1994), é o papel que as organizações têm no processo de liderança. O papel do líder contemporâneo parece relativisado em prol de novas estruturas organizacionais. Blanchard (1996, p. 102-103, grifo do autor) refere-se da seguinte forma: "Quando você vira uma pirâmide ao contrário, filosoficamente, você trabalha para seu pessoal na implementação de visões e metas. Embora pareça secundária esta mudança faz uma grande diferença. A diferença está entre quem é responsável e quem é responsivo."

Ulrich (1996) defende que o fim dos grandes heróis nas organizações está ocorrendo. Para 0 autor, os líderes do futuro serão menos visíveis pelos observadores, porém, mais relevantes para o público interno à organização. A liderança deverá ser mais e mais compartilhada. Ainda sobre liderança compartilhada, afirma-se: "Os líderes do futuro terão de conhecer profundamente a arte de formação de equipes e aprender a trabalhar com equipes abertas. No futuro, as vitórias, em vez de partirem de heróis individuais, virão de equipes que compartilham recursos e aprendem a deixar de lado a ambição pessoal em prol do grupo." (ULRICH, 1996, p. 216). 
Essas visões parecem evidenciar que a liderança está muito mais relacionada a características particulares da organização e a sua arquitetura. Para compreender o que significa arquitetura, Nadler (1994, p. 2) assim se reporta:

Por arquitetura organizacional entendemos uma visão muito mais abrangente dos elementos do projeto dos sistemas social e de trabalho que formam uma grande empresa complexa. A arquitetura inclui, portanto, a estrutura formal, o projeto de práticas de trabalho, a natureza da organização informal ou estilo de operação, e os processos de seleção, socialização e desenvolvimento de pessoal.

Possivelmente a maior influência sobre a arquitetura organizacional tenha sido a evolução da tecnologia da informação. Esta começou a revolucionar o projeto organizacional, ao proporcionar alternativas à hierarquia, como meio principal de coordenação. A combinação do grande potencial de tecnologia da informação, com as grandes exigências do ambiente competitivo, levou à inovação no modelo organizacional (NADLER, 1994). Esse novo modelo está concebendo novos postulados para a problemática da liderança.

Bergamini e Coda (1997) defendem que os líderes hierárquicos perderam o sentido que tinham, pois esse tipo de prerrogativa de poder castra a capacidade de usar experiências e informações. A tecnologia atual rapidamente dissemina todos os tipos de informação, fato que apaga antigas distinções antes respeitadas na era industrial. Para os autores, isso reveste de poder cada camada das organizações atuais, tornando-as flexíveis e enxutas. Neste sentido nas novas organizações moldadas, a partir das rupturas contemporâneas, o cargo passa a ser uma forma grosseira e ultrapassada de avaliar o poder, não refletindo as sutilezas de um real alinhamento. Portanto, para que as organizações atinjam à flexibilidade, o poder não deve derivar do cargo. Esse tipo de poder centralizado é uma das principais características das formas antiquadas de conceber as organizações (BERGAMINI; CODA, 1997).

No contexto atual, cresce a importância das equipes. Para Nadler (1994), o papel da liderança muda, através de um grande número de equipes autônomas, de normas e de valores, e não de regras e de supervisão direta, os quais proporcionam a coesão necessária ao estabelecimento de uma direção e coordenação ativas.

Com o objetivo de facilitar a compreensão das tipologias objeto do estudo, o quadro 1 possibilita uma visão global da temática tratada:

\begin{tabular}{|c|c|c|c|}
\hline TIPOLOGIAS & PERÍODO HISTÓRICO & FOCO DE ESTUDO & AUTORES ESTUDADOS \\
\hline $\begin{array}{c}\text { Dos traços de } \\
\text { personalidade do líder }\end{array}$ & $\begin{array}{c}\text { início do século XX até final } \\
\text { dos anos 40. }\end{array}$ & $\begin{array}{c}\text { as características pessoais do } \\
\text { líder. }\end{array}$ & Brymanm, McClleand, Gardner. \\
\hline Comportamentais & $\begin{array}{c}\text { início dos anos } 50 \text { até o } \\
\text { final dos anos 70. }\end{array}$ & o comportamento do líder. & $\begin{array}{c}\text { Fiedler, Reddin, McGregor, Uhmann, } \\
\text { Hickman. }\end{array}$ \\
\hline Situacionais & anos 60 em diante. & $\begin{array}{c}\text { as variáveis que cercam o } \\
\text { processo de liderança. }\end{array}$ & $\begin{array}{c}\text { Gardner, Reddin, Fieddler, Vroom, } \\
\text { Motta, Bergamini, Hollander. }\end{array}$ \\
\hline Gestão do Sentido & anos 70 em diante. & $\begin{array}{c}\text { os sentidos atribuídos para o } \\
\text { trabalho, a motivação e a } \\
\text { relação entre os objetivos e a } \\
\text { satisfação das necessidades. }\end{array}$ & $\begin{array}{c}\text { Gardner, Smircich, Morgan, Hesberg, } \\
\text { McGregor, Archer, Bergamini, Coda, } \\
\text { Kouzes, Posner. }\end{array}$ \\
\hline $\begin{array}{c}\text { Com ênfase na } \\
\text { arquitetura } \\
\text { organizacional }\end{array}$ & $\begin{array}{c}\text { a liderança como resultante de } \\
\text { aspectos estruturais da } \\
\text { organização. }\end{array}$ & $\begin{array}{c}\text { Cóllins, Porras, Nadler, Bergamini, } \\
\text { Coda, Guia, Gonger, Gadiesh Olivet, } \\
\text { Drucker, Schein. }\end{array}$ \\
\hline
\end{tabular}

\section{Quadro 1 - Síntese de tipologias de liderança.}

Fonte: Bibliografias pesquisadas. 


\section{METODOLOGIA DE PESQUISA}

A população de estudo caracteriza-se por todas as agências do estado de Santa Catarina, totalizando em 196 unidades. A amostra foi composta por nove agências das regiões, conforme quadro 2. Trata-se de agências com mais de 15 funcionários, perfis de varejo misto, as quais são classificadas em um mesmo padrão pelo Banco.

\begin{tabular}{|c|c|c|}
\hline VALE ITAJÁl & MEIO OESTE & DEMAIS REGIŌES \\
\hline Rio do Sul & Joaçaba & \\
\hline Blumenau & Concórdia & \\
\hline & Capinzal & \\
\hline Indaial & Dionísio Cerqueira & Joinville \\
\hline
\end{tabular}

Quadro 2 - Região de localização das agências pesquisadas de um Banco de Varejo Público.

Fonte: Dados secundários.

Dentro de cada agência, foram sorteados nove funcionários, que juntamente com o gerente compõem a amostra final de pesquisa. O presente estudo pode ser delineado como uma pesquisa descritiva. O método utilizado foi o de survey, em conjunto com o método de levantamento (PINSONNEAULT; KRAEMER, 1993). Optou-se pela conveniência na determinação das agências, objeto da escolha para a realização da pesquisa, haja vista um conhecimento maior dos gerentes lotados nas unidades pesquisadas, o que facilitaria o contato, 0 agendamento das visitas, bem como 0 controle para retorno dos questionários. A opção pela amostra por conveniência deve-se ao aspecto operacional, como os já citados, não buscando de nenhuma forma relacionar aspectos que pudessem intervir na dinâmica interna da pesquisa, uma vez que o relacionamento dá-se somente com os gerentes em nível funcional, não do ponto de vista pessoal. Essa é uma técnica não conclusiva, embora válida, já que as pesquisas sociais como as de levantamento partem de universos amplos para as conclusões gerais.

A coleta de dados foi feita através de questionário estruturado com questões fechadas, objetivando determinar 0 perfil de liderança nas referidas agências bancárias. A aplicação do questionário foi precedida através de visita a cada uma das dependências pesquisadas, onde as instruções foram repassadas. Os dados foram trabalhados por meio do software Sphinx Léxica produzido pela SPHINX BRASIL, Canoas, RS. A análise foi delineada no sentido de se estabelecer os perfis de liderança nas nove agências pesquisadas. Dessa forma, os resultados restringem-se as essas unidades e seus respectivos colaboradores, não podendo, portanto, serem extrapolados para outras agências do mesmo banco ou para agências de outros bancos.

Convém ressaltar que a Dependência foi analisada como muito significativa e pouco significativa. A primeira denota, em uma visão global da amostra de pesquisa, que há grandes variações entre as variáveis vistas particularmente e a média da amostra total; enquanto a dependência pouco significativa denota que não há variações significativas entre as variáveis vistas de forma particular e a amostra total. Isso não impede e nem invalida análises de uma tabela, pois o teste trabalha com médias ponderadas, variáveis vistas de forma particular, uma em correlação a outra, as quais podem fornecer várias conclusões para o pesquisador. Essa Dependência é calculada pelo teste Qui². Esse teste mede o grau de dependência em um cruzamento de variáveis. Ele verifica se existe diferença significativa entre as variáveis cruzadas. Também estabelece a diferença entre o número esperado de uma média e o real esperado. 
Os graus de liberdade ( $\mathrm{gl}$ ) representam as variáveis livres para a correlação/cruzamento. No caso da tabela 1, do presente trabalho - Visão dos Colaboradores das Unidades de Trabalho sobre os perfis dos seus líderes -, o grau de liberdade é 32.0 aplicativo, por exemplo, está referenciando, na primeira coluna vertical à esquerda (TC), nove itens e está também referenciando, na primeira coluna horizontal, agência 1, cinco itens, e sobre variáveis de cruzamento 32 elementos.

As probabilidades de ocorrência ou não de um evento é caracterizado por (1-p), que enfatiza a validade da análise, dadas as dependências na visão geral da amostra. Isso mostra que estatisticamente os dados da tabela possuem uma graduação probabilística de validade para uma análise estatística. É uma referência, não eliminando a possibilidade de análise em situações em que (1-p) não seja relevante (análises particulares dos dados de uma tabela).

Exemplificando pela tabela 1, tem-se 0 resultado (810) em cada coluna horizontal. As respostas do questionário podem assumir, dicotomicamente, três dimensões, ou seja: 3-0, 2-1, 1-2; 0-3, 1-2, 2-1. 0 aplicativo SPHINX é linear. Ele trabalha atribuindo uma gradação às respostas, ao passo que o questionário é bidimensional. Digitando uma só vez, o aplicativo atribui somente 33,3\% de ênfase na resposta. Para que 0 aplicativo processe como dimensional, o questionário precisa enfatizar, portanto, três vezes o mesmo resultado. Essa metodologia foi a mesma utilizada por Bazanini (2001).

Para estudar o estilo de gestão de cada gerente há necessidade de verificar esse estilo sob diversas óticas. Primeiramente, é enfocado o estilo de gestão sob a ótica dos não gerentes. A tabela 1 e 0 gráfico 1 ilustram essa visão.

\section{RESULTADOS OBTIDOS}

No tratamento dos dados, foi utilizado o aplicativo Sphinx Léxica, analisando e verificando as dependências de variáveis, por meio do método estatístico "Qui-Quadrado". Com a utilização desse ferramental, o perfil dos respondentes seguiu algumas características. Os respondentes têm um tempo médio de experiência profissional de 15,88 anos, com um mínimo de dois anos e um máximo de 35 anos. No Banco pesquisado, os respondentes estão atuando, em média, há 13,08 anos, com um mínimo de dois anos e um máximo de 31 anos, com um desvio padrão de 10,16. Quando se estratifica a amostra em "Gerentes" e "Não gerentes", o tempo médio de atuação no Banco, para os primeiros, eleva-se para 23,89 anos, com um mínimo de 11 anos e um máximo de 28 anos, apresentando um Desvio Padrão de 5,58 anos. Já os "Não gerentes" atuam no Banco, em média, há 11,88 anos, com um mínimo de dois anos e um máximo de 31 anos, mostrando um desvio padrão de 9,86 anos.

Quanto ao estado civil, a grande maioria dos respondentes é casada $(66,7 \%)$ e $28,7 \%$ são solteiros. Há $2,3 \%$ de separados, $1,1 \%$ de divorciados e 0 mesmo percentual de respondentes que vivem em união estável. Não responderam a esse quesito $4,4 \%$ dos respondentes. Relativamente ao gênero, percebe-se uma predominância significativa do masculino, com $65,5 \%$ dos respondentes. Quando se estratifica a amostra, em função do "Cargo", percebe-se que 100\% dos gerentes são do gênero masculino.

Nas nove agências pesquisadas, não houve assimetrias significativas estatisticamente entre as características acima mencionadas: tempo de banco e experiência profissional, escolaridade, gênero.

\subsection{OS ESTILOS DE GESTÃO}

Para estudar o estilo de gestão de cada gerente, há necessidade de verificar esse estilo sob diversas óticas. Primeiramente, o estilo de gestão sob a ótica dos não gerentes, a tabela 1 e o gráfico 1 mostram essa visão: 
Tabela 1 - Visão dos colaboradores das unidades de trabalho sobre os perfis dos seus líderes

\begin{tabular}{ccccccc}
\hline & TC $\%$ & EC $\%$ & SS $\%$ & GS $\%$ & AO \% & TOTAL $\%$ \\
\hline 1 & $16,5(134)$ & $14,7(119)$ & $21,0(170)$ & $24,9(202)$ & $22,8(185)$ & $100(810)$ \\
\hline 2 & $14,7(119)$ & $17,0(138)$ & $21,6(175)$ & $25,4(206)$ & $21,2(172)$ & $100(810)$ \\
\hline 3 & $15,1(122)$ & $14,3(116)$ & $22,5(182)$ & $23,5(190)$ & $24,7(200)$ & $100(810)$ \\
\hline 4 & $14,8(120)$ & $13,3(108)$ & $22,7(184)$ & $25,7(208)$ & $23,5(190)$ & $100(810)$ \\
\hline 5 & $18,4(149) \mathrm{A}$ & $14,9(121)$ & $21,4(173)$ & $21,7(176)$ & $23,6(191)$ & $100(810)$ \\
\hline 6 & $17,7(143)$ & $15,1(122)$ & $23,5(190)$ & $19,8(160) \mathrm{R}$ & $24,1(195)$ & $100(810)$ \\
\hline 7 & $14,3(116)$ & $15,2(123)$ & $22,8(185)$ & $23,8(193)$ & $23,8(193)$ & $100(810)$ \\
\hline 8 & $18,1(147)$ & $17,4(141) \mathrm{A}$ & $25,6(207) \mathrm{A}$ & $16,7(135) \mathrm{R}$ & $22,2(180)$ & $100(810)$ \\
\hline 9 & $14,8(120)$ & $12,0(97) \mathrm{R}$ & $23,2(188)$ & $27,4(222) \mathrm{A}$ & $22,6(183)$ & $100(810)$ \\
\hline TOTAL & $16,0(1170)$ & $14,9(1085)$ & $\mathbf{2 2 , 7 ( 1 6 5 4 )}$ & $\mathbf{2 3 , 2 ( 1 6 9 2 )}$ & $\mathbf{2 3 , 2 ( 1 6 8 9 )}$ & $100(7290)$ \\
\hline
\end{tabular}

Teorias das Características de Personalidade (TC); Estilos Comportamentais (EC); Sistêmico-Situacionais (SS); Gestão do Sentido (GS); Arquitetura Organizacional (AO).

Fonte: Questionários aplicados

A dependência é muito significativa. Qui² $=62,59, \mathrm{gl}=32,1-\mathrm{p}=99,90 \%$. As células marcadas com A são aquelas para as quais a freqüência real é claramente superior à freqüência teórica. As células marcadas com $R$ são aquelas para as quais a freqüência real é claramente inferior à freqüência teórica. Os valores da tabela são os percentuais em linha estabelecidos sobre 7290 observações. Essa tabela é construída sobre o estrato da população "Não Gerentes" contendo 7290 observações e definido pela filtragem: CARGO $=\{$ Não gerente $\}$

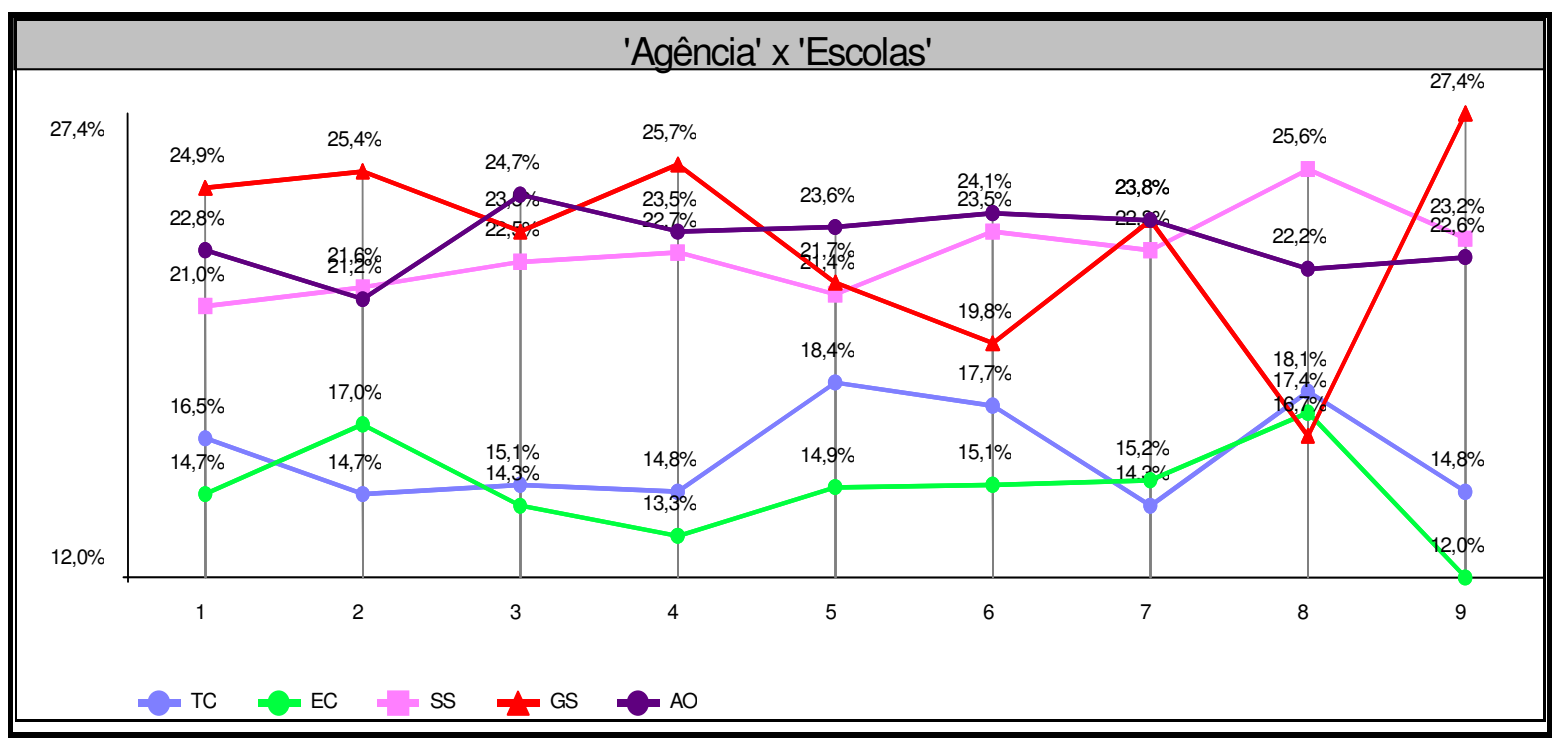

Teorias das Características de Personalidade (TC); Estilos Comportamentais (EC); Sistêmico-Situacionais (SS); Gestão do Sentido (GS); Arquitetura Organizacional (AO).

\section{Gráfico 1 - Visão dos colaboradores das unidades de trabalho sobre os perfis dos seus líderes ou, se expresso, pelo número de citações em percentuais.}

Fonte: Dados coletados

É importante reforçar que se considera a preponderância de uma escola ou outra, em relação ao total das respostas de todos os "Não gerentes", das nove agências analisadas. É possível visualizar 
que, no conjunto das respostas de todos os elementos do estrato "Não Gerentes", as escolas TC, EC e SS guardam uma maior proximidade com as agências 8,6 e 5. E, da mesma forma, a escola GS guarda maior proximidade com as agências 9 e 4. Posto de outra forma, quando se considera todos os respondentes "Não Gerentes", há uma preponderância de citações das escolas TC, EC e SS nas agências 8,6 e 5, enquanto que a escola GS prepondera nas agências 9 e 4. A escola AO é citada mais uniformemente por todas as agências.

As principais conclusões retiradas dessa parte do estudo são:

a) a dependência é significativa. Isso quer dizer que estatisticamente há assimetrias. Portanto, há diferenças entre os perfis dos líderes na ótica dos liderados;

b) nas agências 5, 6 e 8 há uma leve preponderância sobre as demais, em relação à Teoria das Características de Personalidade (TC), conforme tabela 1. Isso fica mais acentuado na agência 5;

c) em relação à Teoria Estilos de Comportamento (EC), há uma certa assimetria. Observa-se que, na agência 7, principalmente, e na 2 há uma tendência maior em relação as demais; ao passo que na agência 9 o nível de respostas, com ênfase nessa tipologia, é menor do que nas demais, com certa ênfase;

d) na tipologia Sistêmica Situacional (SS), houve uma preponderância, um pouco maior na agência 8 em relação as demais;

e) observa-se, na tipologia Gestão do Sentido (GS), a existência de certa assimetria entre as ocorrências nas agências. Houve uma ênfase menor na Agência 8, 6, e 5; ao passo que observa-se uma maior ênfase nessa tipologia nas agências $9,4, e$;

f) numa visão global dos resultados da tabela 1 e gráfico 1, observa-se, no que tange à visão dos colaboradores das agências sobre os perfis do seus líderes, uma certa preponderância nas tipologias Gestão do Sentido(GS) e Arquitetura Organizacional (AO); ao passo que há uma freqüência menor nas tipologias Estilos Comportamentais (EC) e Teorias das Características de Personalidade (TC).

A segunda etapa, na análise da visão dos gerentes, sobre seus próprios perfis de liderança, pode ser vista na tabela 2 e no gráfico 2 :

\section{Tabela 2 - Visão dos gerentes das unidades sobre seus próprios perfis de liderança}

\begin{tabular}{ccccccc}
\hline & TC $\%$ & EC $\%$ & SS $\%$ & GS \% & AO \% & TOTAL \% \\
\hline 1 & $21,1(19)$ & $15,6(14)$ & $27,8(25)$ & $17,8(16)$ & $17,8(16)$ & $100(90)$ \\
2 & $14,4(13)$ & $11,1(10)$ & $24,4(22)$ & $31,1(28)$ & $18,9(17)$ & $100(90)$ \\
3 & $12,2(11)$ & $10,0(9)$ & $17,8(16)$ & $31,1(28)$ & $28,9(26)$ & $100(90)$ \\
4 & $11,1(10)$ & $14,4(13)$ & $21,1(19)$ & $28,9(26)$ & $24,4(22)$ & $100(90)$ \\
5 & $8,9(8)$ & $7,8(7)$ & $20,0(18)$ & $32,2(29)$ & $31,1(28)$ & $100(90)$ \\
6 & $12,2(11)$ & $13,3(12)$ & $24,4(22)$ & $23,3(21)$ & $26,7(24)$ & $100(90)$ \\
7 & $15,6(14)$ & $16,7(15)$ & $21,1(19)$ & $22,2(20)$ & $24,4(22)$ & $100(90)$ \\
8 & $22,2(20)$ & $13,3(12)$ & $20,0(18)$ & $21,1(19)$ & $23,3(21)$ & $100(90)$ \\
9 & $18,9(17)$ & $14,4(13)$ & $18,9(17)$ & $28,9(26)$ & $18,9(17)$ & $100(90)$ \\
TOTAL & $\mathbf{1 5 , 2 ( 1 2 3 )}$ & $\mathbf{1 3 , 0 ( 1 0 5 )}$ & $\mathbf{2 1 , 7 ( 1 7 6 )}$ & $\mathbf{2 6 , 3 ( 2 1 3 )}$ & $\mathbf{2 3 , 8 ( 1 9 3 )}$ & $\mathbf{1 0 0 ( 8 1 0 )}$ \\
\hline
\end{tabular}

Teorias das Características de Personalidade (TC); Estilos Comportamentais (EC); Sistêmico-Situacionais (SS); Gestão do Sentido (GS); Arquitetura Organizacional (AO).

Fonte: Questionários aplicados 
A dependência não é significativa. Qui ${ }^{2}=32,15, \mathrm{gl}=32,1-\mathrm{p}=54,06 \%$. Os valores da tabela são os percentuais em linha, estabelecidos sobre 810 observações. Essa tabela é construída sobre 0 estrato da população "Gerentes", contendo 810 observações, e é definida pela próxima filtragem: $\mathrm{CARGO}=\{$ Gerente $\}$

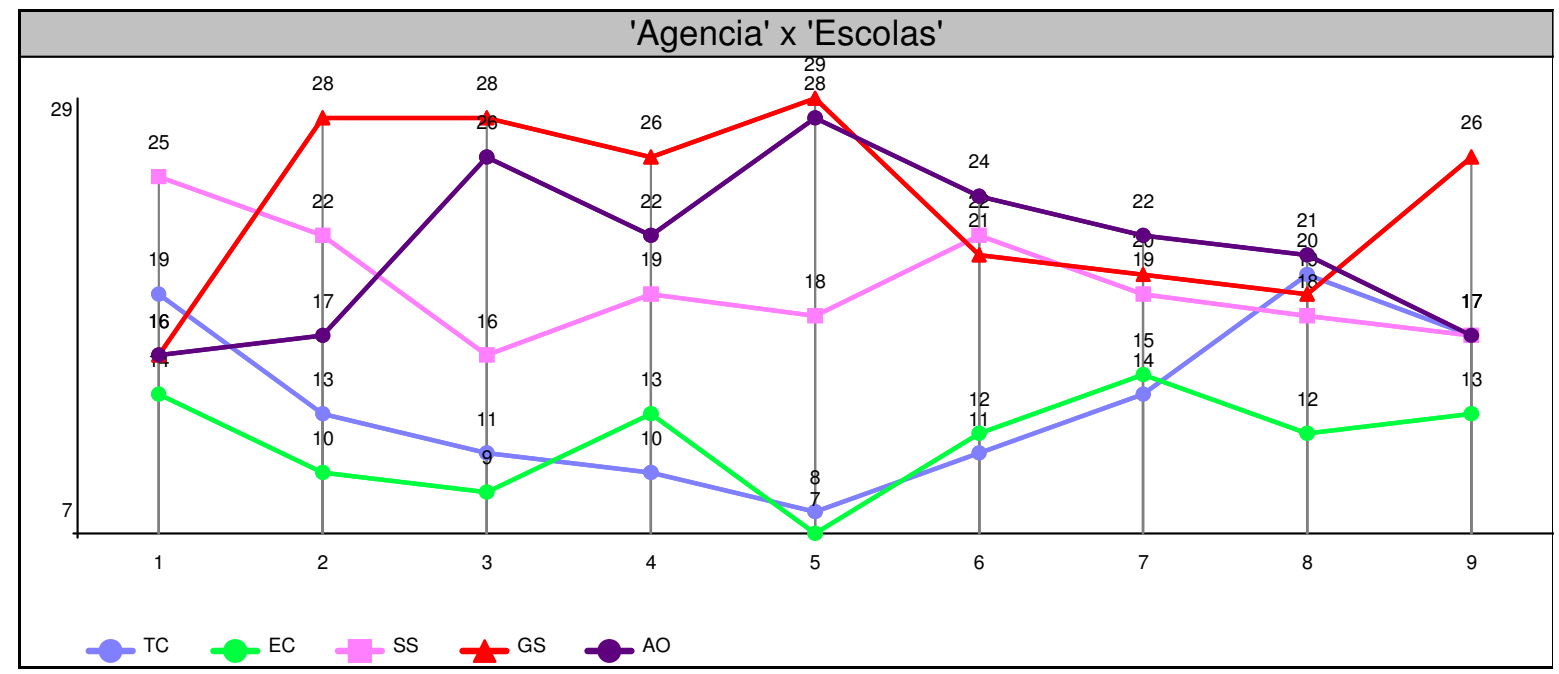

Teorias das Características de Personalidade (TC); Estilos Comportamentais (EC); Sistêmico-Situacionais (SS); Gestão do Sentido (GS); Arquitetura Organizacional (AO).

\section{Gráfico 2 - Visão dos gerentes das unidades sobre seus próprios perfis de liderança ou 0 mesmo gráfico em percentuais.}

Fonte: Dados coletados

As conclusões mais significativas sobre essa etapa da pesquisa são:

a) não há dependência significativa, em uma análise global dos dados da tabela 2, o que em princípio poderia denotar não haver diferenças acentuadas entre os perfis, autopercepção, dos líderes, embora isso não impeça de se fazer análises particulares dentro de cada tipologia e de cada agência;

b) na tipologia Teorias das Características de Personalidade (TC) há uma certa preponderância no perfil dos gerentes das agências 8 e 1; ao passo que a freqüência diminui, com certa ênfase, no gerente das unidades 5 e 4;

c) na tipologia Estilos Comportamentais (EC), observa-se uma ênfase menor nos gerentes das agências 5 e 2, com uma maior ênfase observada para os gerentes das agências $7 \mathrm{e}$ 1 ;

d) na tipologia Sistêmico Situacionais (SS), a ênfase das respostas é menor no gerente da agência 3; ao passo que há uma maior ênfase nas respostas do gerente da agência 1;

e) na tipologia Gestão do Sentido (GS), houve uma menor ênfase nas respostas do gerente da agência 1; ao passo que houve uma maior ênfase nas respostas dos gerentes das agências 2 e 3; 
f) na tipologia Arquitetura Organizacional (AO), a ênfase foi menor nas respostas do gerente da agência 1; ao passo que houve uma maior preponderância nas respostas do gerente da agência 5;

g) em uma visão geral dos dados da tabela 2, percebe-se uma tendência de maior ênfase nas tipologias Gestão do Sentido (GS) e Arquitetura Organizacional (AO); ao passo que se observa menor preponderância em relação às tipologias Estilos Comportamentais (EC) e Teorias das Características de Personalidade (CP).

A escola com maior pontuação foi a Gestão do Sentido (GS) na visão dos nove líderes, não distante estatisticamente da Arquitetura Organizacional (AO); ao passo que pode ser observada uma menor preponderância em relação às tipologias Estilos Comportamentais (EC) e Teorias das Características de Personalidade (TC).

Apesar de não haver dependência significativa nessa relação, observa-se, de forma relevante, a alta pontuação na escola GS, que o líder da agência 5 se concedeu. Ele se avalia com maior ênfase que todos os outros líderes nessa escola. Smircich e Morgan (1997, p. 210), a esse respeito, propõem que:

A pessoa mais facilmente reconhecida como líder organizacional é aquela que se eleva acima e além da especificação da estrutura formal para proporcionar aos membros da organização o sentido de que eles estão organizados, mesmo em meio a um sentimento diário de que, em termos particulares, tudo corre perigo de desintegração.

A visão pessoal de preocupação com o sentido, que os liderados atribuem ao trabalho, pode ser observada como uma possível característica de personalidade do líder da agência 5.

\subsection{COMPARATIVO DE VISÕES: LÍDERES X LIDERADOS}

As tabelas e os gráficos 1 e 2 mostram que há sintonia entre as visões de líderes e liderados nas agências pesquisadas. As coincidências entre a auto-avaliação e avaliação dos liderados pode denotar facetas positivas dos líderes, como observa Bergamini (1994).

$O$ autoconhecimento é apontado como condição de credibilidade, de liderança. Para merecer credibilidade como líder, é necessário, em primeiro lugar, clarificar os próprios valores, que são os padrões através dos quais escolhe-se viver a própria vida. São valores que guiam o como se sente, aquilo que se diz, aquilo que se pensa, como se fazem escolhas e como se age. Uma vez tendo esclarecido os próprios valores, há que traduzi-los em um conjunto de princípios diretores, um credo que possa ser comunicado às pessoas que se espera liderar.

Os resultados parecem corroborar os estudos citados por Reddin (1986), para quem as percepções dos gerentes, quando avaliados dentro de alguns requisitos, como mesma empresa e cargos similares, tendem a ter marcantes aproximações estatísticas.

As palavras de Reddin (1986) ganham o reforço de Gardner (1990, p. 46-47):

Os líderes desenvolvem seus estilos à medida que interagem com seus constituintes. Inclinam-se pelo estilo que parece mais eficaz para lidar com a mistura de elementos que constitui seus grupos de constituintes. A sabedoria convencional diz que existe, por um lado, a imagem pública do líder, tal como percebida pelos seguidores; e, por outro lado, a realidade daquilo que o líder realmente é. Mas muitos pesquisadores concordam que a forma como os seguidores percebem seu líder, também é realidade. Para complicar ainda mais a questão, fica evidente nas histórias das vidas de muitos líderes que a pessoa real e a pessoa percebida pelos seguidores foram gradualmente se fundindo, de forma que a pergunta 'como era a pessoa real?' vai se tornando cada vez mais irrelevante. 


\section{CONCLUSÕES E RECOMENDAÇÕES}

Os dados revelam diferenças significativas no perfil dos líderes, segundo a visão dos liderados, no que se refere à preponderância de uma tipologia em relação a outra e no que se refere à caracterização do líder.

Os líderes das agências 5 e 8 receberam a maior pontuação na tipologia Gestão do Sentido (GS), em relação aos demais, quando comparados com a mesma tipologia, conforme a tabela 1. $\mathrm{Na}$ tipologia Estilos Comportamentais (EC), houve também dependência significativa, acentuando-se essas características nos líderes das unidades 8 e 2; ao passo que o inverso ocorre com o gerente da unidade 9. Na tipologia Sistêmico Situacional (SS), com exceção do líder da agência 8, em que aparece uma relativa ênfase, nos demais há uma relativa similaridade de freqüência. Na Gestão do Sentido (GS), houve novamente uma dependência significativa. Acentua-se a freqüência dessas características no líder da agência 9; ao passo que o inverso ocorre com os gerentes das agências 8 e 6. Na tipologia Arquitetura Organizacional (AO), os resultados não guardam diferenças significantes. Disso depreende-se que os liderados percebem os líderes de forma diferente em relação as suas características e que há diferenças de percepção entre os liderados de algumas agências em relação aos perfis, quando correlacionados com determinadas tipologias.

Os resultados da autopercepção dos líderes das nove agências mostraram diferenças significativas, quando comparadas às freqüências nas cinco tipologias. Acentuam-se em suas autoavaliações uma ênfase na tipologia Gestão do Sentido (GS) e Arquitetura Organizacional (AO); ao passo que ocorre o inverso em relação às tipologia Estilos Comportamentais (EC) e Teorias das Características de Personalidade (TC).

Chama a atenção, no tocante às freqüências do líder da agência 5 , autopercepção. As assimetrias são relevantes, revelando uma freqüência acentuadamente diferente dos demais líderes quando se auto-avaliam. Essas diferenças também são relevantes quando comparadas com a percepção dos liderados. Não se consegue identificar, pelas demais variáveis, como escolaridade média da dependência, escolaridade dos gerentes, gênero e tempo de banco, um fator que possa indicar alguma relação com as freqüências das respostas apresentadas.

$\mathrm{Na}$ análise das variáveis demográficas das agências não foram detectadas diferenças significativas. No cruzamento dessas variáveis com as diversas correntes teóricas, para determinação do perfil do líder, não foi observada nenhuma dependência significativa.

O pressuposto central do presente trabalho era o de que os perfis de liderança dos gerentes das agências não variariam significativamente, em termos de sua percepção e na forma como são percebidos pelos subordinados.

Adicionalmente ao pressuposto central, havia ainda outras questões:

a) haveria mais similaridades que diferenças estatisticamente significantes entre as introspecções dos gestores sobre seus perfis de liderança e as percepções dos liderados;

b) as variáveis demográficas qualitativas que se associam com a percepção que os liderados têm do gestor são: tempo de banco, escolaridade, estado civil e sexo.

A pesquisa confirmou o pressuposto central. Apesar de diferenças em algumas agências, quanto ao perfil e às variações no todo, corroboraram o que apregoava o pressuposto central. Os perfis de liderança dos gestores não variam significativamente, tanto em termos de sua percepção, bem como na forma como são percebidos pelos subordinados. Caso se excluam dos cruzamentos a agência 5, essas similaridades se acentuam, o que enfatizaria, em muito, os aspectos apregoados nos pressupostos. Quanto às variáveis demográficas e suas possíveis associações com as percepções que os liderados têm do gestor, isso não ficou evidente. Não foram observadas relações que pudessem ser destacadas. 
Considerando as diversas mudanças pelas quais têm passado a indústria bancária, como a crescente competitividade no setor, ficou evidente, a partir desta pesquisa, que os gestores das unidades pesquisadas vêm tendo os seus perfis "ajustados" pelos novos contextos, em que estão imersas essas organizações. Para Motta (2001, p. 22), "0 gigantismo das organizações contemporâneas as assemelha a grandes monstros que precisam ser dominados e portanto direcionados". Atualmente, trabalhar em instituições financeiras significa muito mais que apenas efetuar transações de pagamento e recebimento, mas, fundamentalmente, deter conhecimento de mercado de capitais, marketing, relações humanas, técnicas de gerência e administração. A ênfase dos resultados em relação às tipologias Gestão do Sentido (GS) e Arquitetura Organizacional (AO) reforça essa percepção. A preocupação com a motivação, com os objetivos pessoais e organizacionais, características da Gestão do Sentido (GS), bem como a ênfase em elementos ligados a aspectos funcionais da estrutura, além da conformação de novos "modelos" de liderança, características da Arquitetura Organizacional (AO), seguem no mesmo sentido; ao passo que a pouca ênfase em tipologias como as das Características de Personalidade (TC) e Comportamentais (EC) parece enfatizar o lado inverso da questão: aspectos como a figura do líder, o que ele representa e o seu comportamento perdem relevância ante os outros aspectos, como aqueles mencionados em relação às tipologias Gestão do Sentido (GS) e Arquitetura Organizacional (AO).

$O$ presente estudo revestiu-se de um levantamento usado, em conjunto com um survey, tendo um caráter eminentemente qualitativo. As análises quantitativas, feitas apenas a partir das porcentagens, permitiram, tão somente, que se chegasse a conclusões de ordem geral.

O que se avaliou foram opiniões - autopercepções e percepções dos liderados - sobre perfis dos líderes. Os testes estatísticos corroboram a validade de se fazer análises a partir dos dados coletados. Nesses termos, destaca-se que foram atingidos os objetivos de identificar os perfis dos líderes, a partir de suas percepções, como também através das percepções dos liderados.

Não se esperava que os resultados finais obtidos pela presente pesquisa permitissem chegar a conclusões definitivas, no sentido de se evoluir para recomendações práticas, como prescrições comportamentais. Com esta pesquisa espera-se que a Instituição Financeira possa utilizar os resultados para agregar a outros estudos corporativos, que possam vir a se desenvolver sobre a questão, bem como para ter uma referência sobre comportamentos de líderes, embora se ressaltem as limitações de tais afirmações.

\section{REFERÊNCIAS}

ALMEIDA, P. R. A. Estilos de gerência: um estudo sobre as relações entre os tipos de gerência e a missão organizacional. 2002. 155 f. Dissertação (Mestrado em Administração) Universidade de Taubaté (SP), São Paulo, 2002.

BAZANINI, Vidal. Relação entre produtividade e perfil de líderes e liderados: um estudo de caso, 2001. Dissertação (Mestrado em Administração - Centro de Ciências Sociais e Aplicadas, Universidade Regional de Blumenau, Blumenau (SC), (2001).

BERGAMINI, C. W. Liderança: administração do sentido. São Paulo: Atlas, 1994.

BERGAMINI, C. W.; CODA, R.(Org.). Psicodinâmica da vida organizacional. São Paulo: Atlas, 1997.

BOLWIJN, P. T.; KUMPE, T. About facts, fiction and forces in human resource management. Human Systems Management, 1996; 15, 3; p. 161- 172.

CLEMENS, J. K.; MAYER, D. F. Liderança: o toque clássico. São Paulo: Beste Seller, 1989. 
LACOMBE, Francisco; HEILBORN, Gilberto. Administração: princípios e tendências. São Paulo, 2003. FIEDLER, Fred E.; CHEMERS, Martin M. Liderança e administração eficaz. São Paulo: EDUSP, 1981.

FINKELSTEIN, S.; HAMBRICK, D. C. Strategic leadership: top executive and their effects on organizations. Mineapolis/St. Paul: West Educational Publiching, 1996.

GARDNER, John W. Liderança: sucesso e influência a caminho da modernidade. Rio de Janeiro: Record, 1990.

GARDNER, D. G.; CUMMINGS, L. L. Activation theory and jog design: Review and reconceptulization. Research in Organizational Behavior. n. 10; 1988, p. 81-122.

GARDNER, D. G. Activation theory and task design: an empirical test of several new predictions. Journal of Applied Psychology. n. 71, 1986, p. 411-418.

KOUZES, J. M.; POSNER, B. Z. O desafio da liderança. Rio de Janeiro: Campus, 1991.

LIKERT, R. Novos padrões de administração. São Paulo: Livraria Pioneira Editora, 1971.

MOSCOVICI, F. Desenvolvimento interpessoal. Rio de Janeiro: José Olympio, 1995.

NADLER, David A., et al. Arquitetura organizacional. Rio de Janeiro: Campus, 1994.

PINSONNEAULT, A.; KRAEMER, K. L. Survey research methodology in management information system: an assessment.. Journal of Management Information Systems, v. 10, n 2, Autumn, p. 75105, 1993.

REDDIN, W. J. Eficácia gerencial. São Paulo: Atlas, 1986.

SMIRCICH, Linda.; MORGAN, Gareth. A administração do sentido. In: BERGAMINI, Cecília W.; CODA, Roberto (Org.) Psicodinâmica da vida organizacional: Motivação e Liderança. São Paulo: Atlas, 1997. p. $205-230$.

ULRICH, D. Credibilidade x competência. In: HESSELBEIN, F., GOLDSMITH, M. 0 líder do futuro: visões, estratégias e práticas para uma nova era. São Paulo: Futura, 1997.

\section{LEADERSHIP'S STYLES: A STUDY IN THE AGENCIES OF A RETAIL PUBLIC BANK IN SANTA CATARINA}

This paper deals with the verification of the profiles of the managers in the organizational units of a Public retail Bank. The theoretical references for the verification restrict to: Theories of Personality Features (TPF), Mannering Styles (MS), Situational Systematics (SS), Direction Management (DM), and Organizational Architecture (OA). The research methodology is a survey, with the application of a questionnaire with 30 pairs of affirmations; each one of theoretical lines is represented by 12 affirmations. The objective is to identify and to evaluate the styles of management adopted by group 9 managers, in agencies located in Santa Catarina State. The searched agencies keep similarities in relation to its structure and to the public-focus; they act in the interior and have between 15 e 30 employees. The objectives integrally had been reached, being possible to the end of the work to trace the profile of the managers of the studied units. The research did not disclose to significant differences in relations to the profiles tracings for the study. It had a bigger superiority in frequencies in relation to the typologies Direction Management (DM) and Organizational Architecture (OA). It was not evidencing that the demographic variable as time of bank, scholarly, marital status and kind had relation with the gotten results.

Key words: Managers Profiles. Retail Public Bank. Leadership. 